\title{
Images of Aerococcus urinae
}

Mikael Häggström ${ }^{1,2,3}$ and Jonatan Mattila ${ }^{4,5}$

\begin{abstract}
This is a description of an infection in 73 year old man with multiple comorbidities, with images of Aerococcus urinae from resultant blood cultures, showing their alpha hemolytic and Gram-positive properties.

Plain language summary: Aerococcus urinae is a type of bacteria that can lead to infections in the urinary system. This work describes a 73 year old man who had an infection with Aerococcus urinae. Samples of blood and urine were taken from the patient, and when put on blood cells the bacteria weakly changed the color of the blood cells around them. This result is called alpha hemolysis, and can be seen in Image 1. Adding Gram stain to the bacteria turned them violet, and therefore the bacteria were Gram-positive. This can be seen in microscopy in Image 2. The patient was treated with antibiotics.
\end{abstract}

\section{Aerococcus urinae}

Aerococcus urinae is a relatively new species of bacteria in clinical and microbiological practice, first reported in 1989 and designated as a separate species in $1992 .{ }^{[1]} \mathrm{It}$ can cause urinary tract infections, bacteremia / septicemia and/or endocarditis. ${ }^{[2]}$ As a urinary tract pathogen, it causes infections predominantly in elderly persons with local or general predisposing conditions. ${ }^{\left[{ }^{[3]} \text { Aero- }\right.}$ coccus urinae has been estimated to cause approximately $0.31-0.44 \%$ of urinary tract infections. ${ }^{[3]}$

\section{Patient case}

A 73 year old man presented to the emergency department with two days of fatigue, fever and chills. He had a previous history of left arterial cerebral media infarction with expressive aphasia, right side hemiparesis and post-stroke seizures. He suffered from hypertension, atrial fibrillation and aortic stenosis with normal systolic left ventricular function as well as urinary incontinence and prostatic hyperplasia.

In the emergency department he was afebrile and the blood-samples showed a C-reactive protein level of 19

Sundsvall Regional Hospital

${ }^{1}$ Image credits and author of introduction

${ }^{2}$ ORCID: 0000-0002-2732-7631

${ }^{3}$ Author Correspondence: online form

${ }_{4}^{4}$ Author of patient case

${ }^{5}$ Author Correspondence: online form

Licensed under: CC-BY-SA 3.0

Received 01-03-2015; accepted 09-03-2015 $\mathrm{mg} / \mathrm{l}$ (normally less than $5^{[4]}$ or $6^{[5]}$ ) and a leukocyte count of $13.7^{*} 10^{9} / 1$ (normally less than $9.0^{[6]}$ or $10.0^{[7]}$ ). The patient was admitted to the hospital for observation, and after one day on the ward he developed chills and was subfebrile with a tympanic body temperature of $37.6^{\circ} \mathrm{C}$ (normally up to $37.5^{\circ} \mathrm{C}$..$^{[8]}$ Blood and urine samples were taken for culture. Microscopy of the blood samples showed gram-positive cocci. The patient received intravenous cefotaxime. After three days all blood samples and urine samples showed growth of gram-positive catalase-negative cocci Aerococcus urinae (Figures $\mathbf{1}$ and $\mathbf{2}$ ).

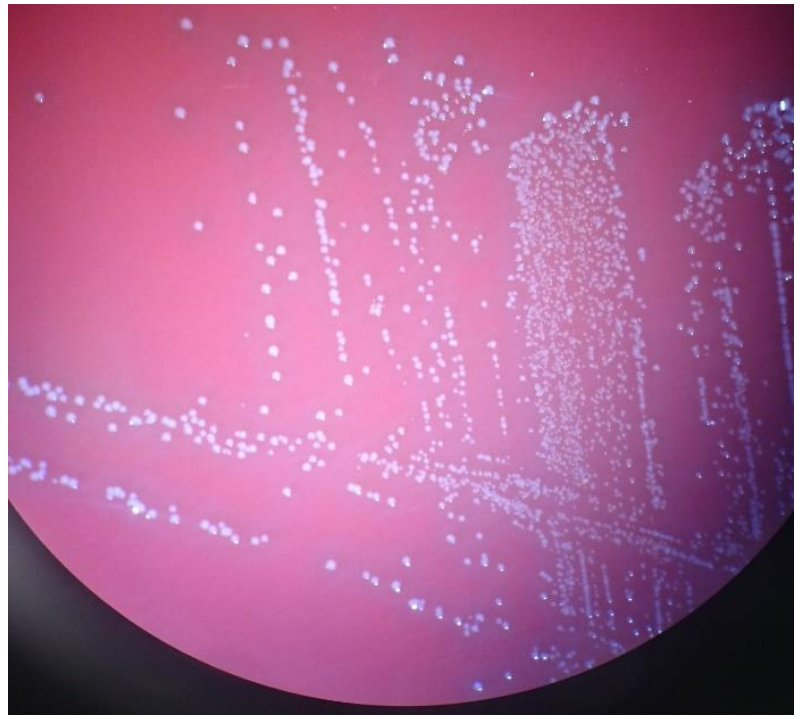

Figure 1 | Blood agar with alpha hemolytic colonies following culture from the patient's blood samples. 


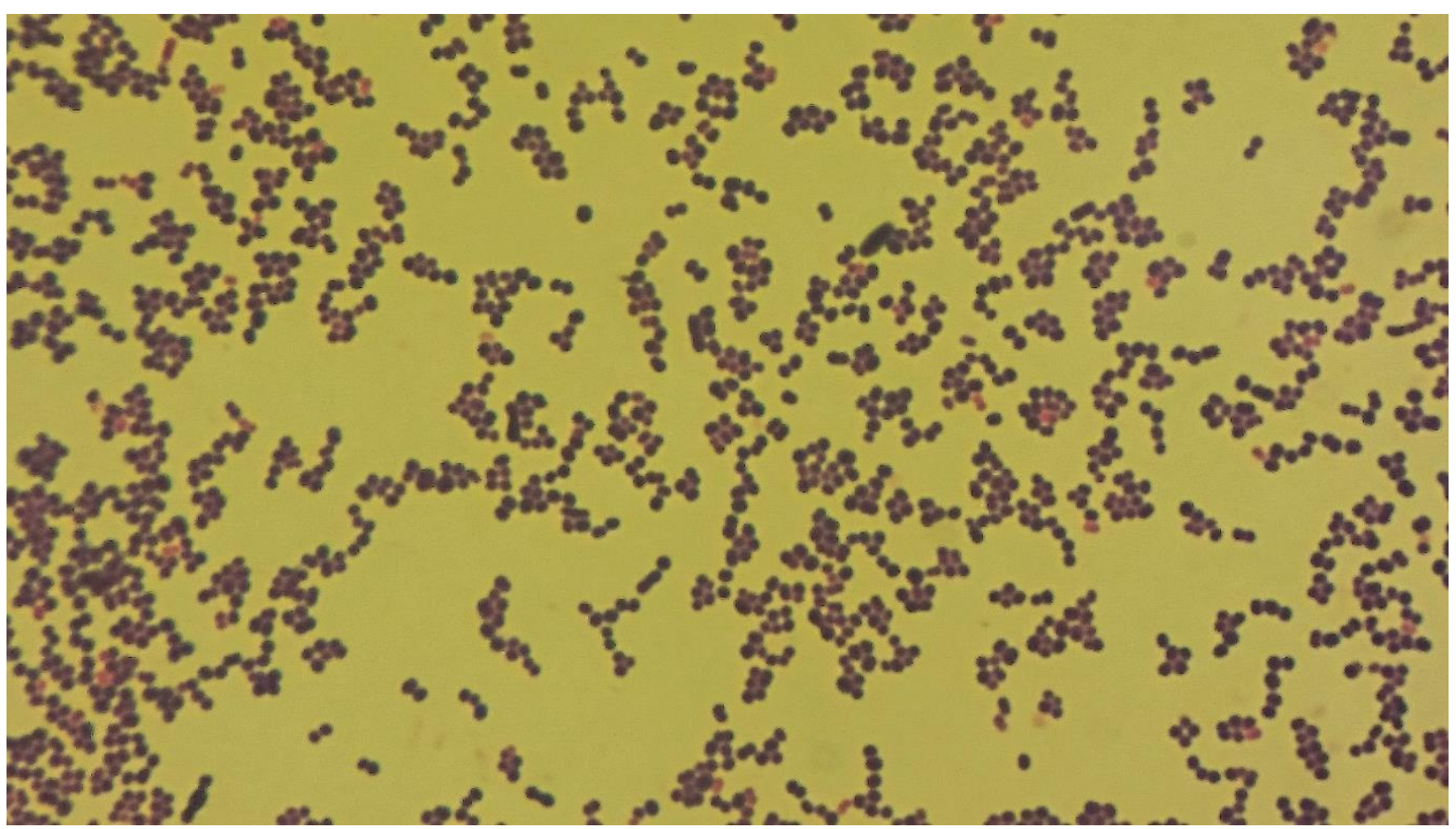

Figure 2 | Micrograph of the bacteria with Gram stain, showing gram-positive cocci.

Confirmation was done with MALDI TOF mass spectrometry.

During the seven days of inpatient care, inflammatory parameters did not reach more than $61 \mathrm{mg} / \mathrm{l}$ for $\mathrm{C}$-reactive protein and $13.7 * 109 / \mathrm{l}$ for leukocyte count. The patient received a cardiac ultrasound due to a systolic murmur, but it did not show any convincing signs of endocarditis.

\section{Notes}

Written consent was obtained from the patient for this publication.

Conflict of Interest: none declared.

\section{References}

1. de Jong, M. F. C.; Soetekouw, R.; ten Kate, R. W.; Veenendaal, D. (2010). "Aerococcus urinae: Severe and Fatal Bloodstream Infections and Endocarditis". Journal of Clinical Microbiology 48 (9): 3445-3447. doi:10.1128/JCM.00835-10. ISSN 0095-1137.

2. Skov, R. (2001). "In vitro antimicrobial susceptibility of Aerococcus urinae to 14 antibiotics, and time-kill curves for penicillin, gentamicin and vancomycin". Journal of Antimicrobial Chemotherapy 48(5): 653-658. doi:10.1093/jac/48.5.653. ISSN 14602091.

3. Schuur PM, Kasteren ME, Sabbe L, Vos MC, Janssens MM, Buiting AG (1997). "Urinary tract infections with Aerococcus urinae in the south of The Netherlands". Eur. J. Clin. Microbiol. Infect. Dis.16 (12): 871-5. PMID 9495666.

4. "C-reactive protein". GPnotebook. Retrieved 2015-03-07.

5. 2730 Serum C-Reactive Protein values in Diabetics with Periodontal Disease A.R. Choudhury, and S. Rahman, Birdem, Diabetic Association of Bangladesh, Dhaka, Bangladesh. (the diabetics were not used to determine the reference ranges)

6. Reference range list from Uppsala University Hospital ("Laborationslista"). Artnr 40284 Sj74a. Issued on April 22, 2008

7. lymphomation.org > Tests \& Imaging $>$ Labs $>$ Complete Blood Count Retrieved on May 14, 2009

8. Tympanic temperature for men, according to: Sund-Levander $\mathrm{M}$, Forsberg C, Wahren LK (2002). "Normal oral, rectal, tympanic and axillary body temperature in adult men and women: a systematic literature review". Scand J Caring Sci 16 (2): 122-8. PMID 12000664 